\title{
Duplicated Origin of the Left Vertebral Artery: A Case Report and Embryological Review
}

\author{
Seunguk Jung, MD, Cheolkyu Jung, MD, Yun Jung Bae, MD, \\ Byung Se Choi, MD, Jae Hyoung Kim, MD
}

The duplicated origin of vertebral artery (VA) is a very rare condition. It could be easily misdiagnosed as an arterial dissection on selective catheter angiography, especially in a patient with acute cerebellar infarction of unknown etiology. We report a patient with an acute cerebellar infarction and duplicated origin of the left VA, which was found during the selective catheter angiography.

Key Words: Vertebral artery; Origin; Duplication

Bilateral vertebral arteries (VAs) generally originated from the first part of the subclavian artery. Multiple variations in the origin of the VA have been reported in the literature. The left VA originating from the aorta is known to be third most common branching pattern of the aorta $[1,2]$. However, the duplicated origin of the VA is quite rare. And it is often misdiagnosed in routine image studies, such as magnetic resonance angiography (MRA) and selective catheter angiography [3]. Anomalous variations in the origin and course of the VA are important for the planning of angiographic and surgical procedure in the posterior circulation. Thus, the possibilities of such variations should be kept

All authors: Department of Radiology, Seoul National University Bundang Hospital, Seongnam, Korea

Received February 7, 2016;

accepted after revision February 13, 2016.

Correspondence to: Cheolkyu Jung, MD, Department of Radiology, Seoul National University Bundang Hospital, 166 Gumi-ro, Bundanggu, Seongnam-si, Gyeonggi-do 463-707, Korea.

Tel. 82.31.714.7625 Fax. 82.31.787.4011

E-mail: jck0097@gmail.com

This is an Open Access article distributed under the terms of the Creative Commons Attribution Non-Commercial License (http://creativecommons.org/licenses/by-nc/3.0) which permits unrestricted non-commercial use, distribution, and reproduction in any medium, provided the original work is properly cited. in mind before the examination or procedure. We report a case of duplicated origin of the left VA observed on selective catheter angiography, with a review of the embryological explanation and previous literature.

\section{CASE REPORT}

A 63-year-old woman presented with sudden onset vertigo and was diagnosed with an acute infarction in the left cerebellum on October 17, 2015. On the brain magnetic resonance imaging (MRI), an acute infarction was observed in the territory of the left superior cerebellar artery (SCA) (Fig. 1A). Magnetic resonance angiography showed a mild irregularity in both proximal VAs and an occlusion in the left SCA (Fig. 1B). For further evaluation, we performed a diagnostic cerebral angiography. The SCA was completely recanalized, and there was no definite abnormality in both VAs. Incidentally, we observed an unopacified streaming at the level of C5 during the selective catheter angiography of the left VA originated from the left subclavian artery (Fig. 2A, B). And the medial limb of the left VA arising from the aortic arch could be found on the selective catheter angiography, which was not observed on the MRA. The dominant, lateral limb of the left VA was originated from the left subclavian 
artery (Fig. 2A, B) and the small, medial limb was originated directly from the aortic arch between the left common carotid artery and the left subclavian artery (Fig. 2C, D). They joined at the transverse foramen of the fifth cervical vertebra.

A right-to-left shunt was suspected on the transcranial doppler using an agitated saline solution with blood. A pulmonary arteriovenous malformation (AVM) in the right lung was detected by transesophageal echocardiography and chest computed tomography. With an elevated level of D-dimer with $421 \mathrm{ng} / \mathrm{ml}$, the pulmonary AVM was suspected as a source of embolus causing an acute cerebellar infarction.

\section{DISCUSSION}

The left VA arising from the aortic arch is the third most common pattern of aortic arch branching with an incidence of 2.4-5.8\% [1, 2]. However, the duplicated origin of the VA is quite rare and the majority cases were found incidentally. We reported a patient with duplicated origin of the left VA, and it could be suspected when an unopacified streaming was observed during the selective catheter angiography of the dominant VA limb arising from left subclavian artery. It could be potentially misdiagnosed as an arterial dissection, if the possibility of duplicated origin of the VA was not considered.

In a previous literature, 26 cases with duplicated origin of the VA were reported before 1998 and have been summarized in detail [3]. Since 1998, we found 15 additional cases with duplicated origin of the VA, including three patients with bilateral duplicated origin of VAs (Table 1). Overall, 24 patients had a duplicated origin of the left VA, including our case, and 21 patients had a duplicated origin of the right VA. Among them, three patients had a bilateral duplicated origin of VAs. The medial limb directly from the aorta and the lateral limb from the subclavian artery was the most common pattern of the duplicated left VA (21 of 24 , $87.5 \%$ ). Two patients had origins of both limbs in the subclavian arteries. And only one patient had origins of both limbs in the aortic arch. Contrast to the left side, the duplicated limbs arising from the ipsilateral subclavian artery was the most common pattern in the right side (18 of $21,85.7 \%)$. The medial limb from brachiocephalic trunk or aorta was observed in two patients [3]. And there was no available data about the origins of the duplicated VA in one patient [4]. The union levels varied from the $\mathrm{C} 3$ to $\mathrm{C} 6$ level.

Embryologically, the VA is formed by the longitudi-
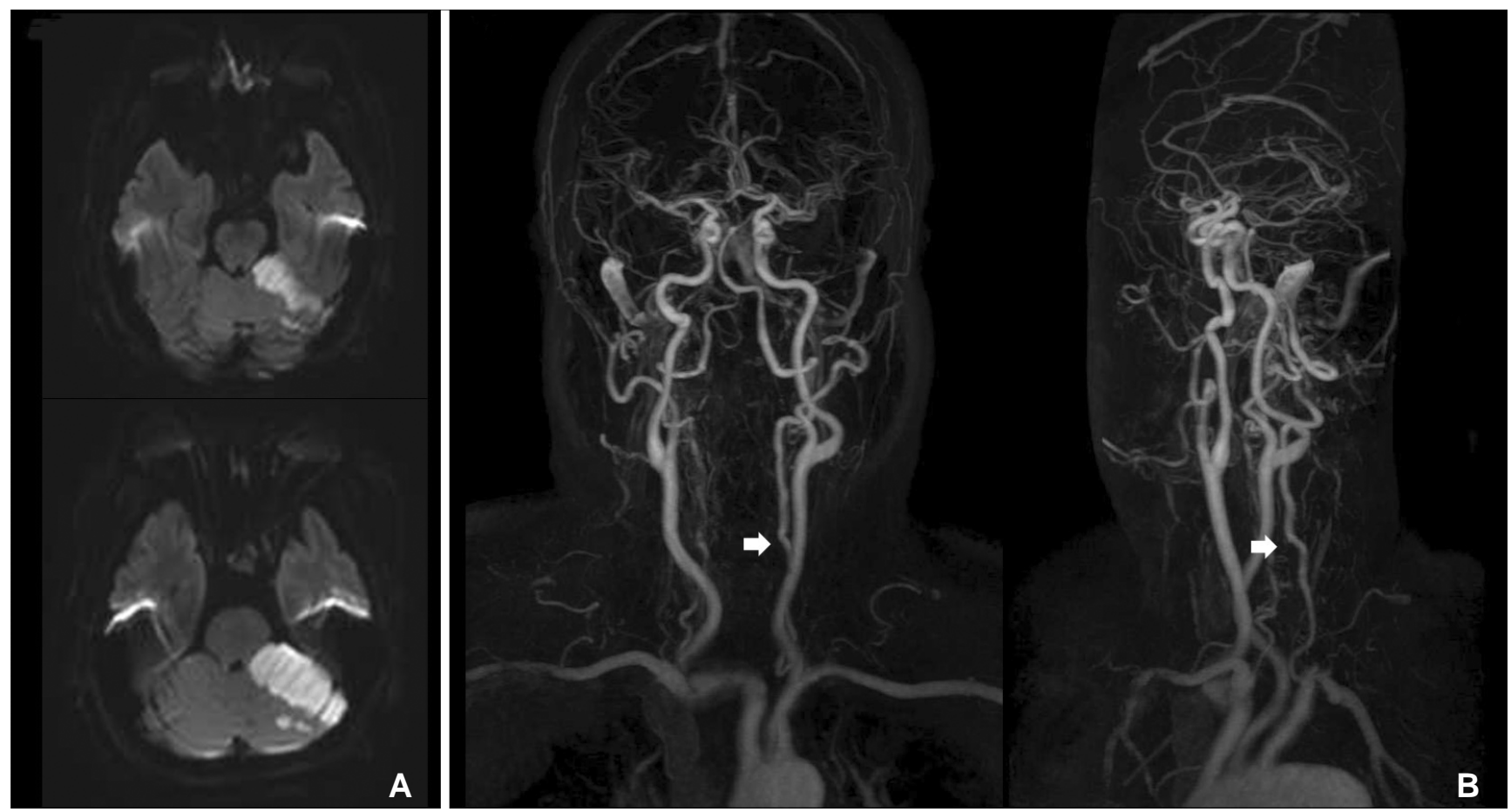

Fig. 1. Brain magnetic resonance image of the patient. Diffusion weighted image showed an acute infarction in the left upper cerebellum of superior cerebellar artery territory $(\mathbf{A})$. Contrast enhanced magnetic resonance angiography did not show the duplicated origin of the left vertebral artery (B). 

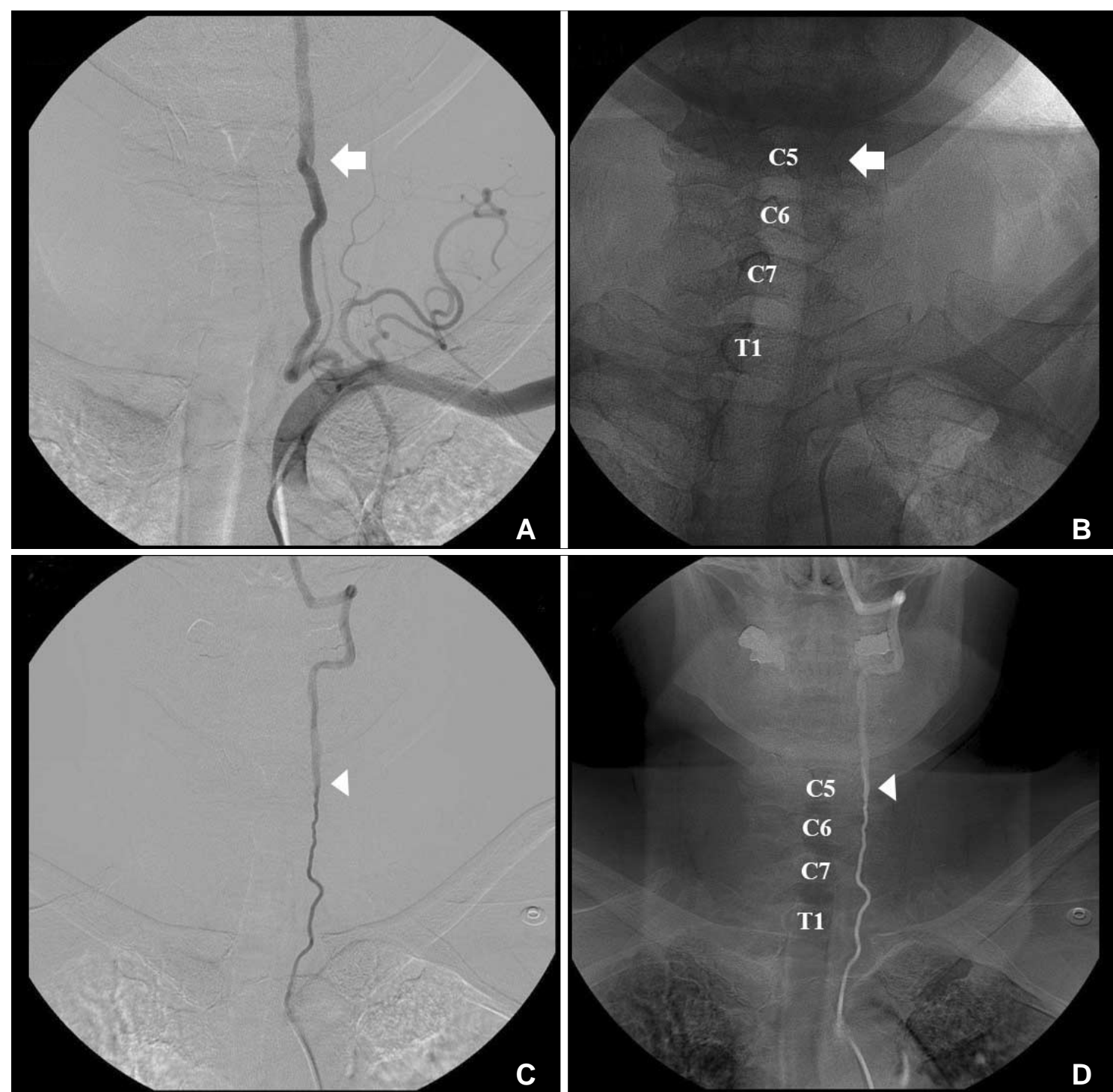

Fig. 2. Left subclavian artery angiograms, anteroposterior view (A and $\mathbf{B})$, of the larteral (dominant) limb of the duplicated origin of the left vertebral artery, showing filling defect at C-5 level (white arrow). Selective angiograms, anteroposterior view (C and $\mathbf{D})$, showing the medial limb of the left vertebra artery (arrowhead), which enters around the C-5 level.

nal anastomoses between the cervical intersegmental arteries. And the connections of the intersegmental arteries to the dorsal aorta eventually regress, except the seventh intersegmental artery, which develops into the proximal subclavian artery containing an origin of the VA. The left VA originated from the left subclavian artery and enters the sixth transverse foramen. The variation of an aortic origin of the left VA results from degeneration of the connection with the seventh intersegmental artery and a persistence of a higher intersegmental artery [5]. In this situation, the VA commonly enters the fifth transverse foramen [6]. Likewise, persistence of the left fourth or fifth cervical intersegmental arteries and the normal origin from the seventh intersegmental artery result in a duplicated origin of the left VA (Fig. 3). The left fourth or fifth intersegmental arteries originate from the aorta between the left common carotid artery and left subclavian artery [3, 7]. In contrast to the left side, duplicated origins of the right VA are usually arising from the right subclavian or brachiocephalic artery when the fourth or fifth cervical intersegmental artery is persistent. Aortic origin of the right VA may occur in the following rare conditions. First, the right seventh cervical intersegmental artery is originated from the descending aorta distal to the left subclavian artery. Second, the right fourth or fifth cervical intersegmental artery is originated from the ascending aorta, and the right subclavian artery is originated from the descending aorta distal to the left subclavian artery [3]. 


\section{Duplication of the Left Vertebral Artery Origin}

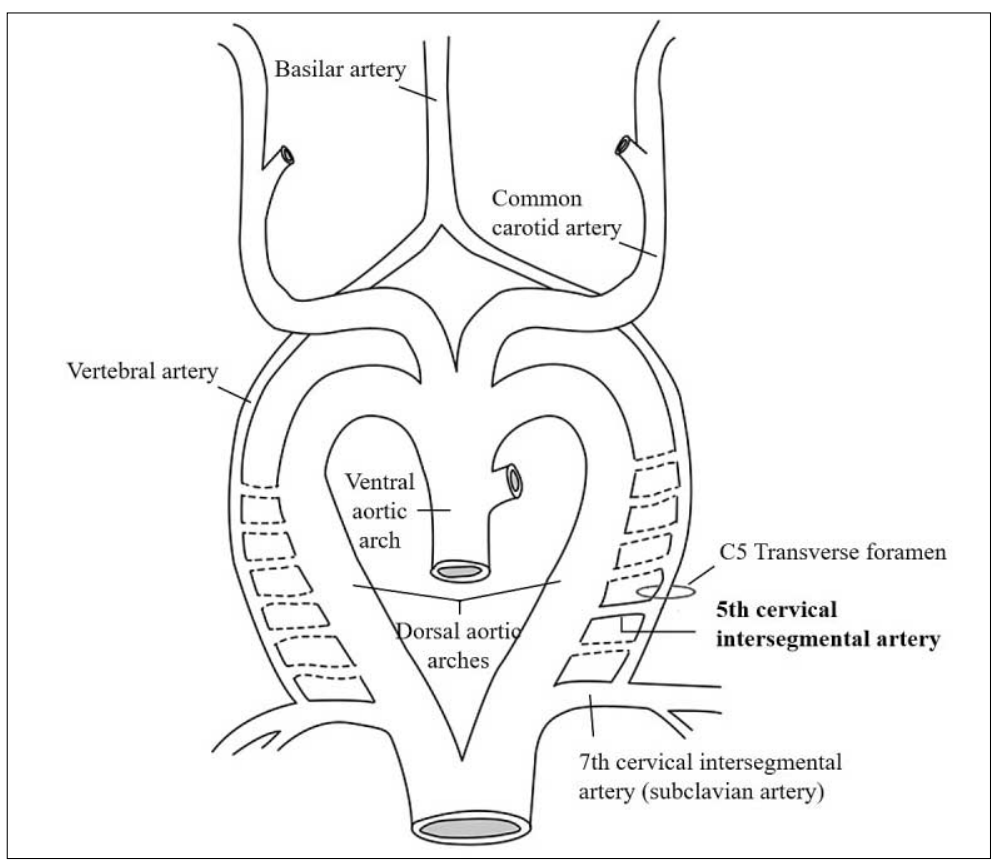

Fig. 3. The embryonic development of vertebral artery shows the vertebral arteries developing from longitudinal anastomosis of the cervical intersegmental arteries. The fifth intersegmental artery is persistent which leads to a duplicated origin from the subclavian artery and the aortic arch. (Modified from Thomas AJ et al. 2008 [5])

Table 1. Previous with Duplicated Origin of the Vertebral Artery since 1998

\begin{tabular}{|c|c|c|c|c|c|c|c|c|}
\hline Author (Year) & Sex & Age & Laterality & Image & Medial limb & Lateral limb & Union level & Disease or status \\
\hline \multirow[t]{2}{*}{ Ionete C. et al. (2006) } & \multirow[t]{2}{*}{$M$} & \multirow[t]{2}{*}{83} & Right & \multirow[t]{2}{*}{ MRA* } & RSA & RSA & C4-5 & \multirow[t]{2}{*}{ Cognitive imparment } \\
\hline & & & Left & & LSA & LSA & C5-6 & \\
\hline \multirow[t]{2}{*}{ Mordasini P. et al. (2008) } & \multirow[t]{2}{*}{ M } & \multirow[t]{2}{*}{48} & Right & \multirow[t]{2}{*}{ MRA $^{*}$} & RSA & RSA & C4-5 & \multirow[t]{2}{*}{ Cerebral infarction } \\
\hline & & & Left & & Aorta & LSA & $C 4-5$ & \\
\hline \multirow{2}{*}{$\begin{array}{l}\text { Rameshbabu. CS. } \\
\text { et al. (2014) }\end{array}$} & \multirow[t]{2}{*}{$M$} & \multirow[t]{2}{*}{36} & Right & \multirow[t]{2}{*}{$\mathrm{CTA}^{*}$} & RSA & RSA & C4-5 & \multirow[t]{2}{*}{ Dizziness } \\
\hline & & & Left & & Aorta & LSA & C5-6 & \\
\hline \multirow[t]{2}{*}{ Goddard et al. (2001) } & $\mathrm{F}$ & 66 & Right & MRA $^{s}$ & RSA & RSA & NA & \multirow{2}{*}{$\begin{array}{l}\text { Cerebral infarction } \\
\text { ICA occlusion }\end{array}$} \\
\hline & M & 49 & Right & $M_{R} A^{s}$ & NA & NA & NA & \\
\hline Satti SR. et al. (2007) & $\mathrm{F}$ & 53 & Right & DSA & RSA & RSA & C3 & headache \\
\hline Harnier et al (2008) & $\mathrm{F}$ & 61 & Right & MRA@ & RSA & RSA & NA & Dizziness \\
\hline Thomas AJ. et al. (2008) & $\mathrm{F}$ & 49 & Right & DSA & RSA & RSA & $\mathrm{C} 6$ & Aneurysm \\
\hline Melki et al. (2012) & $\mathrm{M}$ & 51 & Right & CTA, MRA & RSA & RSA & C5-6 & Cerebellar infarction \\
\hline $\begin{array}{l}\text { Mahmutyazicioglu } \\
\text { et al. (1998) }\end{array}$ & M & 62 & Left & US and CTA & LSA & LSA & NA & TIA \\
\hline Satti SR. et al. (2007) & $\mathrm{M}$ & 62 & Left & DSA & Aorta & LSA & NA & Presyncope \\
\hline Kim DW et al. (2009) & $\mathrm{F}$ & 42 & Left & DSA & Aorta & LSA & C5 & AVF \\
\hline Polguj et al. (2013) & $\mathrm{M}$ & 43 & Left & CTA & LSA & LSA & C5-6 & ICA dissection \\
\hline Shin SW et al. (2013) & $\mathrm{F}$ & 51 & Left & CTA, MRA and DSA & Aorta & LSA & C4 & Aneurysm \\
\hline Kendi ATK et al. (2014) & $\mathrm{F}$ & 59 & Left & CTA and MRA & Aorta & LSA & $\mathrm{C} 5-6$ & Aneurysms \\
\hline Our case & $\mathrm{F}$ & 63 & Left & DSA & Aorta & LSA & C4 & Cerebellar infarction \\
\hline
\end{tabular}

*3D contrast-enhanced magnetic resonance angiography (MRA) of the neck and transverse source image from the $2 \mathrm{D}$ time-of-flight (TOF) MRA, ${ }^{*}$ Multidetector 64-row computed tomography (MDCT) angiography, ${ }^{\$} 2 \mathrm{D}$ TOF MRA of the cervical vessels and 3D TOF MRA of the cervical and intracranial vessels, ${ }^{\circledR}$ maximum intensity projection (MIP)-reconstruction of a TOF MRA

Note: RSA, right subclavian artery; LSA, left subclavian artery; BCA, brachiocephalic artery; MRA, magnetic resonance angiography; CTA, computed tomography angiography; DSA, digital subtraction angiography; TIA, transient ischemic attack; NA, not assessable 


\section{Seunguk Jung, et al.}

The majority of previous cases and our case had no clinical implication from the duplicated origin of the VA, although it has been suggested that the duplicated origin of the VA might be a predisposing factor for certain cerebrovascular pathologies, such as aneurysm or dissection $[8,9]$. To take hypothetical example, it could be the other route for an interventional procedure for the posterior circulation or the potential collateral channel in case of a proximal, extracranial VA occlusion. For all that the duplicated origin of the VA may have in the clinical implication mentioned above, there should be more evidence supporting the hypothesis that the rare variation of the VA could be related to a pathologic condition or therapeutic intervention.

In conclusion, the duplicated origin of the VA is rare, but then it is a good example to explain the embryological development of the VA. While it could be a false negative on the contrast enhanced MRA, we could incidentally find the duplicated origin of the left VA on selective catheter angiography by recognizing the unopacifed streaming in the original path of the VA.

\section{References}

1. Liechty JD, Shields TW, Anson BJ. Variations pertaining to the aortic arches and their branches; with comments on surgically important types. Q Bull Northwest Univ Med Sch 1957;31:136

2. Haughton V, Rosenbaum A. The normal and anomalous aortic arch and brachiocephalic arteries. Radiology of the Skull and Brain 1974;2:1145-1163

3. Komiyama M, Nakajima H, Yamanaka K, Iwai Y. Dual origin of the vertebral artery--case report. Neurol Med Chir 1999;39:932937

4. Goddard AJ, Annesley-Williams D, Guthrie JA, Weston M. Duplication of the vertebral artery: report of two cases and review of the literature. Neuroradiology 2001;43:477-480

5. Thomas AJ, Germanwala AV, Vora N, Prevedello DM, Jovin T, Kassam A, et al. Dual origin extracranial vertebral artery: case report and embryology. J Neuroimaging 2008;18:173-176

6. Padget DH. Designation of the embryonic intersegmental arteries in reference to the vertebral artery and subclavian stem. Anat Rec 1954;119:349-356

7. Anderson RJ. A New Abnormality in connection with the Vertebral Artery. J Anat Physiol 1880;14:249

8. Melki E, Nasser G, Vandendries C, Adams D, Ducreux D, Denier C. Congenital vertebral duplication: a predisposing risk factor for dissection. J Neurol Sci 2012;314:161-162

9. Kendi AT, Brace JR. Vertebral artery duplication and aneurysms: 64-slice multidetector CT findings. Br J Radiol 2009;82:e216-218 